\title{
Efeito da Temperatura Ambiente sobre o Desempenho e Características de Carcaça de Frangos de Corte Alimentados com Dieta Controlada e Dois Níveis de Energia Metabolizável ${ }^{1}$
}

\author{
Adhemar Rodrigues de Oliveira Neto을 Rita Flávia Miranda de Oliveira ${ }^{3}$, Juarez Lopes \\ Donzele $^{3}$, Horacio Santiago Rostagno ${ }^{3}$, Rony Antonio Ferreira ${ }^{2}$, Humberto do Carmo \\ Maximiano ${ }^{4}$, Eliane Gasparino 5
}

RESUMO - O efeito da temperatura ambiente sobre desempenho e características de carcaça de frangos de corte alimentados com dieta controlada e dois níveis de energia metabolizável foi avaliado. Cento e sessenta frangos de corte machos Hubbard, de 21 dias de idade, com $791 \pm 4,12 \mathrm{~g}$ de peso médio inicial, foram alojados em ambiente com temperatura termoneutra $\left(23,3 \pm 0,58^{\circ} \mathrm{C}\right)$ ou quente $\left(32,3 \pm 0,31^{\circ} \mathrm{C}\right)$ até 42 dias de idade. O delineamento experimental foi inteiramente casualizado, em esquema fatorial 2 x 2 (nível de energia metabolizável [3075 e $3300 \mathrm{kcal}$ de EM/kg] e temperatura ambiente [termoneutro e calor]), com cinco repetições e oito aves por unidade experimental. As aves receberam iguais quantidades de ração nos dois ambientes. Ganho de peso e conversão alimentar foram influenciados negativamente pelo calor. Embora os pesos absolutos da carcaça e dos cortes (coxa, sobrecoxa, pernas e peito) e o rendimento de peito dos frangos mantidos sob estresse de calor tenham reduzido, o rendimento de carcaça aumentou. Os pesos, absoluto e relativo, das penas foram menores para os animais mantidos no calor. Os pesos, absoluto e relativo, da gordura abdominal foram maiores para os frangos de corte criados no calor. A alta temperatura ambiente reduziu os pesos, absoluto e relativo, de coração, fígado, moela e intestinos, entretanto, o peso relativo dos pulmões e do proventrículo não foi influenciado. O estresse de calor influenciou negativamente o desempenho, reduziu o rendimento de peito e o peso de órgãos vitais, bem como aumentou a gordura abdominal de frangos de corte, independente do nível energético da ração.

Palavras-chave: alimentação pareada, carcaça, desempenho, frangos de corte, órgãos, temperatura ambiente

\section{Effect of Environment Temperature on Performance and Carcass Characteristics in Broilers Pair-Fed and Two Levels of Metabolizable Energy}

\begin{abstract}
The effect of environmental temperature on performance and carcass characteristics in broilers pair-fed and two levels of metabolizable energy was evaluated. One hundred and sixty Hubbard male broilers, with 21 days of age and $791 \pm 4.12 \mathrm{~g}$ average initial weight were allotted either under thermoneutral environment $\left(23.3 \pm 0.58^{\circ} \mathrm{C}\right)$ or under hot environment $\left(32.3 \pm 0.31^{\circ} \mathrm{C}\right)$ up to 42 days of age. A completely randomized design in a $2 \times 2$ factorial arrangement (level of metabolizable energy [ 3075 and $3300 \mathrm{kcal}$ of $\mathrm{ME} / \mathrm{kg}$ ] and environmental temperature, [thermoneutral and hot]) with five replicates and eight birds per experimental unit was used. The broilers received the same quantity of diet in both environments. The weight gain and feed: gain of the broiler heat stressed was negatively affected by high environmental temperature. Although the absolute carcass and cuts (drumstick, tight, legs and breast) weight and breast yield of the birds decreased in hot environmental temperature, carcass yield increased. The absolute and relative weight of broiler feathers was lower in hot condition. The absolute and relative weight of abdominal fat of the broiler heat stressed was higher for the broilers in the hot environment. The high environmental temperature determined a decrease in the absolute and relative weight of heart, liver, gizzard and gut, but it did not affect lungs and proventriculus relative weights. The heat stress negatively affected the performance, decreased the breast yield and essential organ weights, and increased the abdominal fat of broilers independent of the energy level of the diet.
\end{abstract}

Key Words: pair-fed, carcass, performance, broiler, organs, environmental temperature

\section{Introdução}

As aves, por serem animais homeotérmicos, mantêm a sua temperatura corporal por meio de mecanismos fisiológicos e comportamentais.

O calor gerado pelos processos metabólicos e o recebido do ambiente devem ser dissipados do corpo da ave para o meio, a fim de que a homeotermia seja mantida. Essas trocas de calor são realizadas com gasto mínimo de energia em ambiente termoneutro. Entretanto, quando submetidas a altas temperaturas, as aves apresentam maior dificuldade em manter sua temperatura corporal, porque não têm glândulas sudoríparas e a camada isolante da cobertura de

\footnotetext{
${ }^{1}$ Parte da Tese de Mestrado do primeiro autor - Projeto Financiado pela FAPEMIG.

2 Estudante de Doutorado do DZO/UFV.

3 Professor do DZO/UFV.

${ }^{4}$ Estudante de Zootecnia do DZO/UFV - Bolsista de Iniciação Científica - CNPq.

${ }^{5}$ Estudante de doutorado do DB/UFV.
} 
penas dificulta a troca de calor com o meio. O aumento da taxa respiratória é, portanto, o mecanismo termorregulatório mais eficiente para dissipar o calor corporal em condições de estresse de calor. Dessa maneira, o requerimento de energia para mantença das aves expostas a diferentes temperaturas ambientes pode ser alterado.

O menor consumo de ração observado em frangos de corte mantidos em estresse de calor é uma tentativa de reduzir a produção de calor metabólico. Essa redução do consumo de ração é acompanhada de piora no ganho de peso e na conversão alimentar, conforme constatado por BAZIZ et al. (1996).

O peso da carcaça, o rendimento dos cortes nobres, a deposição de gordura abdominal (BAZIZ et al., 1996) e o peso das penas (GERAERT et al., 1996a) e dos órgãos abdominais de frangos de corte também podem ser reduzidos pela alta temperatura ambiente.

Dessa forma, faz-se necessário avaliar a influência da temperatura ambiente sobre o desempenho e as características de carcaça e peso de órgãos, em frangos de corte machos Hubbard, no período de 22 a 42 dias de idade, recebendo alimentação controlada e dois níveis de energia metabolizável.

\section{Material e Métodos}

O experimento foi conduzido no Laboratório de Bioclimatologia Animal do Departamento de Zootecnia do Centro de Ciências Agrárias da Universidade Federal de Viçosa, em Viçosa, MG.

Foram utilizados 160 frangos de corte machos Hubbard, com peso inicial médio inicial de 791 $\pm 4,12$, no período de 22 a 42 dias de idade, sendo 80 mantidos em ambiente termoneutro $\left(23,3 \pm 0,58^{\circ} \mathrm{C}\right)$ e $80 \mathrm{em}$ estresse de calor $\left(32,3 \pm 0,31^{\circ} \mathrm{C}\right)$. $\mathrm{O}$ delineamento experimental utilizado foi o inteiramente casualizado em esquema fatorial $2 \times 2$ (dois níveis de energia metabolizável, 3075 e $3300 \mathrm{kcal}$ de EM/kg, e duas temperaturas ambientes, conforto e calor), com cinco repetições e oito aves por unidade experimental.

Durante o período inicial (1 a 21 dias de idade), as aves foram criadas em galpão convencional, sob manejo e alimentação tradicionais, descritos por GOMES et al. (1996). Completados os 21 dias de idade, os frangos foram transferidos para as câmaras climáticas, onde foram alojados em baterias, com compartimentos de $0,85 \times 0,85 \mathrm{~m}$, providos de comedouro e bebedouro tipo calha. As baterias foram colocadas em salas climatizadas com temperatura e umidade relativa controlada. As condições ambientais das salas foram monitoradas, três vezes ao dia, por meio de termômetros de bulbo seco e bulbo úmido, globo negro e máxima e mínima, mantidos no centro da sala.

$\mathrm{Na}$ formulação das rações experimentais (Tabela 1), os níveis de proteína bruta (PB), minerais e vitaminas recomendados por ROSTAGNO et al. (1996) foram aumentados em $15 \%$, para garantir consumo adequado destes nutrientes. As aves mantidas em ambos os ambientes experimentais receberam ração controlada, correspondendo, em média, a 93,5\% do consumo voluntário de aves mantidas em ambiente de alta temperatura. Para determinação do consumo voluntário das aves em ambiente de alta temperatura, utilizou-se um grupo adicional de 80 frangos de corte, distribuídos em grupos de oito por compartimento, mantidos em câmaras climáticas, sob condições de estresse de calor.

A água foi fornecida à vontade e trocada três vezes ao dia para evitar seu aquecimento nos bebedouros. A cada troca, mediu-se o consumo de água das aves.

O programa de luz foi contínuo (24 horas de luz artificial) durante todo o período experimental, utilizando-se lâmpadas fluorescentes de 75 watts.

No final do período experimental ( $42^{\circ}$ - dia), após 6 horas de jejum, quatro aves com peso mais próximo da média de cada compartimento foram abatidas por meio de deslocamento cervical.

As aves foram pesadas no início e no final do período experimental para cálculo do ganho de peso. $\mathrm{O}$ consumo de ração foi medido a cada três dias. No final do período, determinou-se a conversão alimentar.

$\mathrm{Na}$ determinação do rendimento de carcaça, foi considerado o peso da carcaça eviscerada, em relação ao peso vivo da ave depois do jejum.

A gordura abdominal foi constituída pelo tecido adiposo presente ao redor da cloaca, da bursa de Fabricius e dos músculos abdominais adjacentes, conforme descrito por SMITH (1993).

Os cortes de coxa, sobrecoxa, peito e pernas (coxa + sobrecoxa) foram pesados em balança com precisão de $1 \mathrm{~g}$ e seus rendimentos foram calculados em relação ao peso da carcaça eviscerada.

Os órgãos (coração, fígado, moela, proventrículoe pulmões) foram cortados longitudinalmente e pendurados à sombra, durante 30 minutos, para que o sangue escorresse, sendo pesados em seguida. O intestino foi aberto em toda sua extensão, sendo retirado seu conteúdo, lavado e, após escorrido, o excesso de água foi pesado. O peso relativo (\%) dos órgãos também foi 
Rev. bras. zootec.

Tabela 1 - Composição centesimal das rações experimentais Table 1 - Percentage composition of the experimental diets Ingrediente Nível de energia Ingredient metabolizável (kcal/kg) Metabolizable energy level ( $\mathrm{kcal} / \mathrm{kg})$

\begin{tabular}{|c|c|c|}
\hline & \multicolumn{2}{|c|}{ level (kcal/kg) } \\
\hline & 3075 & 3300 \\
\hline Milho $(7,86 \% \text { PB })^{1}$ & 46,30 & 46,30 \\
\hline Corn grain $(7.86 \% C P)$ & & \\
\hline Farelo de soja $(46,27 \% \text { PB })^{1}$ & 40,50 & 40,50 \\
\hline
\end{tabular}

Soybean meal $(46.27 \% \mathrm{CP})$

Fosfato bicálcico

Dicalcium phosphate

Calcário

$1,83 \quad 1,83$

Limestone

Bacitracina de zinco (10\%)

Zinc bacitracin

BHT (antioxidante)

BHT (antioxidant)

Cloreto de colina

Choline chlorate

Sal

Salt

Premix mineral $^{2}$

Mineral mix ${ }^{2}$

Premix vitamínico

Vitamin mix ${ }^{3}$

DL-metionina

DL-metionine

Coban 200 (anticoccidiano) $^{4} \quad 0,05 \quad 0,05$

Óleo de soja

$6,35 \quad 8,92$

Soybean oil

Inerte (Caulim)

$2,92 \quad 0,35$

Inert

Composição calculada ${ }^{5}$

Calculated composition ${ }^{5}$

\begin{tabular}{lcc}
\hline $\begin{array}{l}\text { Energia metabolizável (kcal/kg) } \\
\text { Metabolizable energy }\end{array}$ & 3075 & 3300 \\
$\begin{array}{l}\text { Proteína bruta (\%) } \\
\text { Crude protein }\end{array}$ & 22,50 & 22,50 \\
$\begin{array}{l}\text { Lisina (\%) } \\
\text { Lysine }\end{array}$ & 1,269 & 1,269 \\
Ca $(\%)$ & 1,034 & 1,034 \\
P disponível (\%) & 0,453 & 0,453 \\
Available P & 0,206 & 0,206 \\
$\mathrm{Na}(\%)$ & \\
\hline
\end{tabular}

${ }^{1}$ Valores obtidos no Laboratório de Nutrição Animal do DZO/UFV, de acordo com metodologia descrita por SILVA (1990) (Values obtained on the Animal Nutrition Laboratory of DZO/UFV, according to SILVA [1990]).

2 Premix mineral por kg de ração (Mineral mix per kg of diet) - Mn, $60 \mathrm{~g}$; $\mathrm{Fe}, 80$ g; Zn, 50 g; Cu, 10 g; Co, 2 g; I, 1 g; e veículo q.s.p. (q.s.p excipient), $500 \mathrm{~g}$.

${ }^{3}$ Premix vitamínico por $\mathrm{kg}$ de ração (Vitamin mix per $\mathrm{kg}$ of diet) - vit. A 15.000.000 UI, vit. $D_{3}-1.500 .000$ UI, vit. E - 15.000 UI, vit. $B_{1}-2,0 \mathrm{~g}$, vit. $B_{2}-4,0 \mathrm{~g}$, vit. $B_{6}-3,0 \mathrm{~g}$, vit. $B_{12}-0,015 \mathrm{~g}$, ácido nicotínico (nicotinic acid) - $25 \mathrm{~g}$, ácido pantotênico (pantotenic acid) $-10 \mathrm{~g}$, vit. $\mathrm{K}_{3}-3,0 \mathrm{~g}$, ácido fólico (folic acid) - $1,0 \mathrm{~g}$, bacitracina de zinco (zinc bacitracin) $10 \mathrm{~g}$, selênio (selenium) - $250 \mathrm{mg}$, antioxidante BHT (BHT antioxidant) $10 \mathrm{~g}$ e veículo q.s.p. (q.s.p. excipient) - $1.000 \mathrm{~g}$.

${ }^{4}$ Monensina sódica, $200 \mathrm{~g} / \mathrm{kg}$ (Sodic monensine, $200 \mathrm{~g} / \mathrm{kg}$ ).

${ }^{5}$ Composição calculada segundo ROSTAGNO et al. (1996), com exceção da proteína bruta (Calculatedcompositionaccording to ROSTAGNO et al. [1996], except for crude protein). calculado em relação ao peso da carcaça eviscerada.

As análises estatísticas das variáveis de desempenho (ganho de peso, conversão alimentar e consumo de proteína e energia metabolizável), rendimento de cortes nobres e pesos, absoluto e relativo, de órgãos, penas e gordura abdominal foram realizadas utilizando-se o programa SAEG (Sistema para Análises Estatísticas e Genéticas), desenvolvido na UNIVERSIDADE FEDERAL DE VIÇOSA - UFV (1982).

\section{Resultados e Discussão}

Os valores médios de temperatura e umidade relativa e do índice de temperatura de globo e umidade, registrados no interior das câmaras climáticas, são mostrados na Tabela 2.

Os resultados de desempenho dos frangos de corte, no período de 22 a 42 dias de idade, recebendo rações com dois níveis de energia metabolizável (EM) e submetidos a diferentes temperaturas ambientais, são apresentados na Tabela 3. Não ocorreu interação entre o nível de energia metabolizável e a temperatura ambiente para nenhuma das características de desempenho avaliadas.

Os consumos de energia metabolizável (CEM) e proteína bruta $(\mathrm{CPB})$ das aves não variaram significativamente entre os ambientes térmicos, o que pode ser explicado pelo fato de as aves, nos dois ambientes, terem consumido quantidades similares de ração.

As aves submetidas ao estresse de calor apresentaram consumo de água $37 \%$ superior $(\mathrm{P}<0,01)$ às mantidas no ambiente termoneutro. Este resultado está de acordo com os de MAY e LOTT (1992) e BELAY e TEETER (1993, 1996), que também constataram aumento no consumo de água nos frangos de corte submetidos ao calor. Segundo relatos de CURTIS (1983) e MACARI (1996), aves submetidas a altas temperaturas apresentam maior turnover de água. $\mathrm{O}$ aumento no consumo de água reflete o grau de estresse a que as aves estavam mantidas e a conseqüente tentativa destas em favorecer a perda de calor corporal para o ambiente.

A temperatura ambiente influenciou $(\mathrm{P}<0,01) \mathrm{o}$ ganho de peso (GP), que foi $16 \%$ menor nas aves mantidas sob estresse de calor em relação às mantidas em conforto térmico. Resultados semelhantes foram obtidos por GERAERT et al. (1996b), que, trabalhando com frangos de corte, avaliando alimentação ad libitum 
Tabela 2 - Condições ambientais observadas nas câmaras climáticas para frangos de corte mantidos em ambiente de conforto térmico e estresse de calor

Table 2 - Environment conditions observed in the climatic chambers for broilers maintained under thermoneutral and heat stress environment

\begin{tabular}{lcc}
\hline $\begin{array}{l}\text { Variáveis climáticas } \\
\text { Climate elements }\end{array}$ & $\begin{array}{c}\text { Termoneutro } \\
\text { Thermoneutral }\end{array}$ & $\begin{array}{c}\text { Estresse de calor } \\
\text { Heat stress }\end{array}$ \\
\hline $\begin{array}{l}\text { Temperatura do ar }\left({ }^{\circ} \mathrm{C}\right) \\
\text { Air temperature }\end{array}$ & $23,3 \pm 0,58$ & $32,3 \pm 0,31$ \\
$\begin{array}{l}\text { Umidade relativa }(\%) \\
\text { Relative humidity }\end{array}$ & $64 \pm 2,73$ & $60 \pm 1,59$ \\
$\begin{array}{l}\text { Temperatura de globo negro }\left({ }^{\circ} \mathrm{C}\right) \\
\text { Black globe temperature }\end{array}$ & $23,4 \pm 0,81$ & $32,2 \pm 0,29$ \\
$\begin{array}{l}\text { Indice de temperatura de globo e umidade (ITGU) } \\
\text { Humidity and black globe index }(\mathrm{HBGI})\end{array}$ & $71 \pm 1,01$ & $83 \pm 0,36$ \\
\hline
\end{tabular}

Tabela 3 - Desempenho de frangos de corte no período de 22 a 42 dias mantidos em ambiente termoneutro e estresse de calor, recebendo a mesma quantidade de ração

Table 3 - Performance of broilers pair-fed from 22 to 42 days of age maintained under thermoneutral and heat stress enviroment

\begin{tabular}{|c|c|c|c|c|c|c|}
\hline \multirow{4}{*}{$\begin{array}{l}\text { Variáveis } \\
\text { Variables }\end{array}$} & \multicolumn{6}{|c|}{$\begin{array}{c}\text { Temperatura ambiente } \\
\text { Environmental temperature }\end{array}$} \\
\hline & \multirow{2}{*}{\multicolumn{3}{|c|}{$\begin{array}{c}\text { Termoneutro }\left(23,3^{\circ} \mathrm{C}\right) \\
\text { Thermoneutral } \\
\text { Nível de EM }(\mathrm{kcal} / \mathrm{kg}) \\
\text { ME level }\end{array}$}} & \multirow{2}{*}{\multicolumn{3}{|c|}{$\begin{array}{c}\text { Estresse de calor }\left(32,3^{\circ} \mathrm{C}\right) \\
\text { Heat stress } \\
\text { Nível de EM }(\mathrm{kcal} / \mathrm{kg}) \\
\text { ME level }\end{array}$}} \\
\hline & & & & & & \\
\hline & 3075 & 3300 & $\begin{array}{l}\text { Média } \\
\text { Average }\end{array}$ & 3075 & 3300 & $\begin{array}{l}\text { Média } \\
\text { Average }\end{array}$ \\
\hline $\begin{array}{l}\text { Consumo água }(\mathrm{mL}) \\
\text { Water intake }\end{array}$ & 4779 & 4947 & $4863^{b}$ & 8129 & 7399 & $7764^{\mathrm{a}}$ \\
\hline $\begin{array}{l}\text { Peso final }(\mathrm{g}) \\
\text { Final weight }\end{array}$ & 1831 & 1882 & $1857^{\mathrm{a}}$ & 1684 & 1684 & $1684^{b}$ \\
\hline $\begin{array}{l}\text { Ganho de peso (g) } \\
\text { Weight gain }\end{array}$ & 1042 & 1089 & $1066^{\mathrm{a}}$ & 893 & 893 & $893^{b}$ \\
\hline $\begin{array}{l}\text { Consumo ração }(\mathrm{g}) \\
\text { Feed intake }\end{array}$ & 2044 & 2020 & 2032 & 2025 & 2005 & 2015 \\
\hline $\begin{array}{l}\text { Conversão alimentar } \\
\text { Feed:gain ratio }\end{array}$ & 1,96 & 1,86 & $1,91^{b}$ & 2,27 & 2,25 & $2,26^{\mathrm{a}}$ \\
\hline $\begin{array}{l}\text { Consumo EM }(\mathrm{kcal}) \\
\text { ME intake }\end{array}$ & 6285 & 6666 & 6476 & 6228 & 6618 & 6423 \\
\hline $\begin{array}{l}\text { Consumo de proteína }(\mathrm{g}) \\
\text { Protein intake }\end{array}$ & 460 & 455 & 457 & 456 & 451 & 453 \\
\hline
\end{tabular}

Médias seguidas por letras diferentes, na linha, são diferentes pelo teste $\mathrm{F}(\mathrm{P}<0,05)$.

Means, within a row, followed by different letters are different by $F$ test $(P<.05)$.

no conforto $\left(22^{\circ} \mathrm{C}\right)$, ad libitum no calor $\left(32^{\circ} \mathrm{C}\right)$ e pairfeeding no conforto com o grupo do calor, constataram que cerca de $50 \%$ da redução do crescimento das aves, mantidas sob calor, foram relacionados a outros fatores, à exceção do consumo de ração.

De forma similar ao GP, constatou-se que a alta temperatura $\left(32^{\circ} \mathrm{C}\right)$ determinou aumento $(\mathrm{P}<0,01)$ de $19 \%$ na conversão alimentar (CA) das aves. Resultados semelhantes foram obtidos por GERAERT et al. (1996a), que também verificaram que o estresse de calor no período entre a $4^{\mathrm{a}}$ e $6^{\mathrm{a}}$ semanas de vida influenciou negativamente o GP e a CA de frangos de corte, recebendo quantidades similares de ração.
Quando mantidos em estresse de calor, os frangos de corte reduzem seu crescimento em maior proporção que o consumo de ração, o que resulta em pior índice de conversão alimentar, conforme relatado por diversos autores (GERAERT et al., 1996a; BAZIZ et al., 1996). No entanto, os mamíferos parecem reagir de forma diferente em relação ao ambiente térmico em que são mantidos. Em trabalhos conduzidos com leitões em crescimento (RINALDO e LE DIVIDICH, 1991) e ratos machos (CHRISTON et al., 1984), observou-se que os animais mantidos no ambiente de calor tiveram melhor eficiência alimentar, comparados àqueles mantidos no conforto. 
Rev. bras. zootec.

OLIVEIRA et al. (1997), entretanto, constataram que temperaturas ambientais termoneutra, $22^{\circ} \mathrm{C}$, e quente, $32^{\circ} \mathrm{C}$, não influenciaram a conversão alimentar de leitões machos em crescimento, alimentados ad libitum.

Os pesos absolutos (g) e o rendimento (\%) de carcaça, coxa, sobrecoxa e peito de frangos de corte machos Hubbard, aos 42 dias de idade, mantidos em ambientes de termoneutralidade e estresse de calor são apresentados na Tabela 4. Não ocorreu interação entre a temperatura ambiente e o nível de energia metabolizável para os pesos, absoluto e relativo, da carcaça, coxa, sobrecoxa, pernas e gordura abdominal, com exceção do peso relativo de peito.

A temperatura ambiente influenciou $(\mathrm{P}<0,01) \mathrm{o}$

Tabela 4 - Pesos absoluto e relativo de carcaça, cortes nobres, gordura abdominal e penas de frangos de corte aos 42 dias mantidos em ambiente termoneutro e estresse de calor, recebendo a mesma quantidade de ração

Table 4 - Absolute and relative weight of carcass, parts, abdominal fat and feathers of broilers pairfed at 42 days of age, maintained under thermoneutral environment and heat stress environments

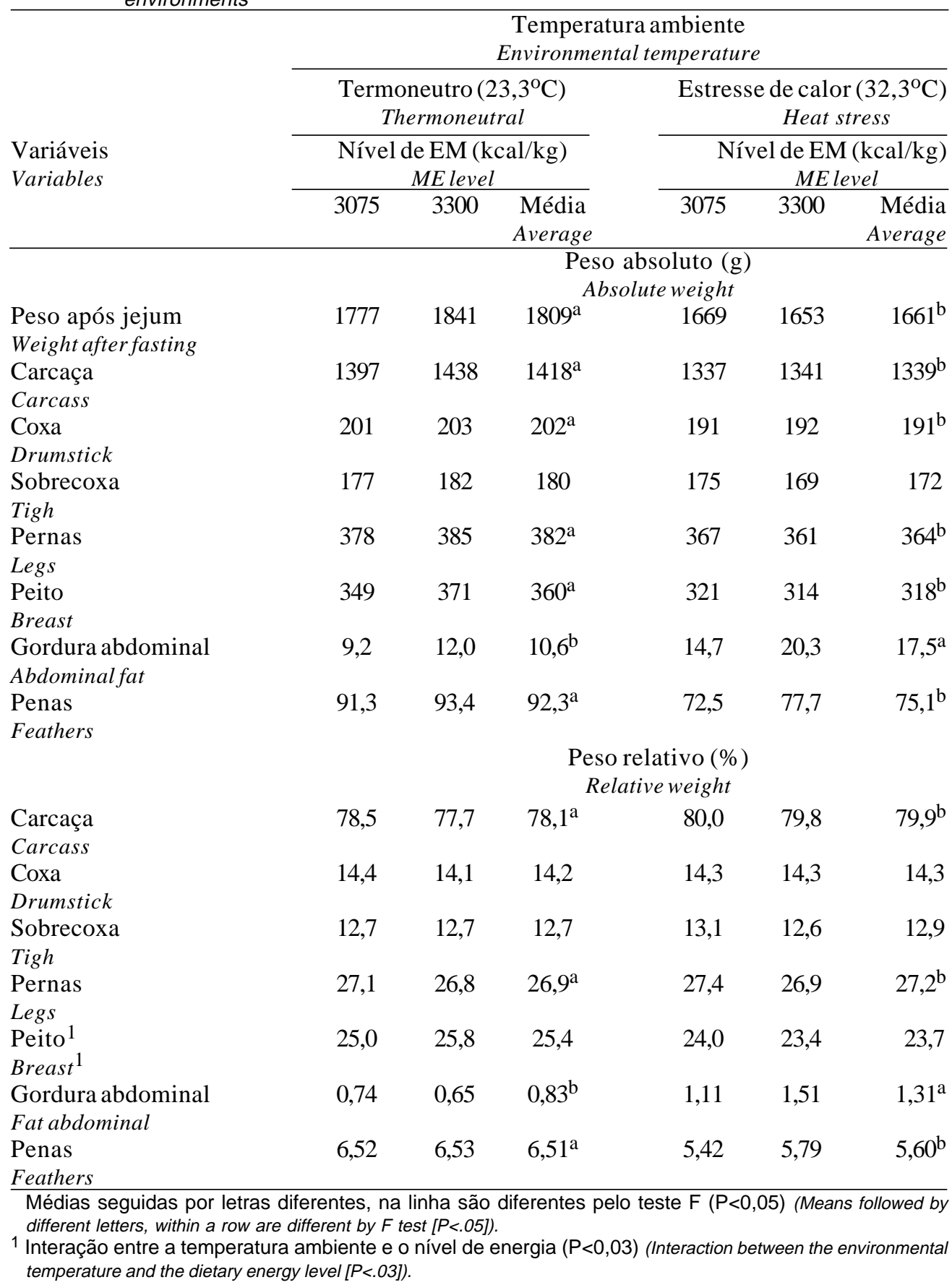


peso absoluto da carcaça, coxa e peito, que foram 5,$5 ; 5,4$; e $11,9 \%$, respectivamente, menores nos frangos mantidos a $32^{\circ} \mathrm{C}$.

Embora o peso da carcaça das aves mantidas no calor $(1339 \mathrm{~g})$ tenha sido menor em relação às do conforto térmico (1417 g), observou-se que o rendimento foi $2,3 \%$ maior $(\mathrm{P}<0,01)$, o que pode ser explicado pelo menor peso absoluto das penas e dos órgãos (Tabela 4).

Com relação ao rendimento de coxa e sobrecoxa, não se observou variação em razão da temperatura ambiente. No entanto, o rendimento de perna (coxa + sobrecoxa) foi $1,1 \%$ maior no calor.

Verificou-se interação entre a temperatura ambiente e o nível de energia da ração para o rendimento de peito $(\mathrm{P}<0,03)$, sendo que as aves mantidas em ambiente termoneutro apresentaram maior rendimento de peito, quando o nível de energia aumentou de 3075 para $3300 \mathrm{kcal}$ de EM/kg de ração, enquanto, no estresse de calor, o rendimento de peito foi reduzido, quando os frangos consumiram a ração com maior nível de energia (Tabela 4). Estes resultados estão coerentes com aqueles obtidos por BAZIZ et al. (1996), que também observaram redução na produção de carne de peito com aumento no ganho de músculo de perna. Segundo esses autores, o efeito diferenciado da exposição ao calor sobre os músculos de peito e perna pode estar relacionado às características energéticas e aos respectivos substratos (glicose e ácidos graxos), além de modificações no metabolismo protéico (síntese e degradação).

Com relação à gordura abdominal, constatou-se que as aves mantidas a $32^{\circ} \mathrm{C}$ (Tabela 4) apresentaram maiores $(\mathrm{P}<0,01)$ valores de pesos absoluto e relativo desse tecido. Este resultado corrobora os encontrados por BAZIZ et al. (1996) e YUNIANTO et al. (1997), que constataram maior deposição de gordura abdominal nos frangos de corte mantidos em altas temperaturas, em relação aos mantidos na termoneutralidade.

O aumento na gordura abdominal pode estar associado à redução do tamanho de órgãos metabolicamente ativos (Tabela 5) e da deposição de proteína de peito, o que disponibilizou maior quantidade de energia para deposição como gordura no ambiente de calor.

De acordo com HABEEB et al. (1992), causas fisiológicas, como redução no consumo de alimentos e na liberação de hormônios termogênicos, são as responsáveis pela redução do metabolismo basal, diminuindo a produção de calor. No entanto, KOONG et al. (1983) e FERREL e KOONG (1986) associaram a redução na exigência de mantença à diminuição da massa de órgãos internos e à atividade metabólica diminuída desses órgãos em ratos em crescimento. Todavia, essas alterações fisiológicas conduzem à menor produtividade dos animais.

Segundo BAZIZ et al. (1996), o metabolismo basal e a atividade física das aves são reduzidos no calor, o que poderia resultar em maior quantidade de energia, disponível para o crescimento. Contudo, essa energia extra é armazenada essencialmente como gordura abdominal em suínos e gordura subcutânea e abdominal em aves.

De acordo com GERAERT et al. (1996b), aves expostas ao calor apresentaram menores concentrações plasmáticas de triiodotironina e corticosterona, podendo intensificar a deposição de gordura corporal.

Os pesos, absoluto (g) e relativo (\%), dos órgãos comestíveis (coração, fígado e moela) e não-comestíveis (pulmão, proventrículo e intestino) das aves mantidas em diferentes temperaturas ambientes encontram-se na Tabela 5. Verificou-se redução no peso absoluto de coração, fígado, moela, proventrículo, intestino $(\mathrm{P}<0,01)$ e pulmões $(\mathrm{P}<0,03)$ e no peso relativo de coração, fígado, moela e intestinos $(\mathrm{P}<0,01)$, em razão do estresse de calor. Contudo, o peso relativo do proventrículo e dos pulmões não foram influenciados pela temperatura ambiente, sugerindo que o aumento verificado nos respectivos pesos absolutos ocorreu em razão do crescimento corporal das aves. Diferentes autores (ZANUSSO, 1998, em aves, e OLIVEIRA et al., 1997, em suínos) também observaram redução dos pesos absolutos e relativos de órgãos, em razão da alta temperatura ambiente.

A redução observada no peso dos órgãos de aves expostas a altas temperaturas ambientais constitui-se em ajuste fisiológico, na tentativa de reduzir a produção de calor corporal. Diversos autores relatam haver menor produção de calor corporal em aves (EFFECT..., 1981; YUNIANTO et al., 1997) e novilhos (OLE MIARON e CHRISTOPHERSON, 1992) mantidos em alta temperatura.

Os resultados obtidos permitem inferir que a redução nos pesos dos órgãos ocorreu em razão dos efeitos da temperatura ambiente sobre outros parâmetros, que não o consumo de ração, uma vez que o consumo das aves não variou entre os ambientes, evidenciando tentativa das aves dem se adaptar à condição ambiental desfavorável.

Os pesos absoluto e relativo das penas dos frangos de corte machos, na fase de 22 a 42 dias de idade, 
Rev. bras. zootec.

Tabela 5 - Pesos absoluto e relativo de órgãos de frangos de cortes aos 42 dias mantidos em ambiente termoneutro e estresse de calor, recebendo a mesma quantidade de ração

Table 5 - Absolute and relative weight organs of broilers pair-fed at 42 days of age, and maintained under thermoneutral and heat stress environments

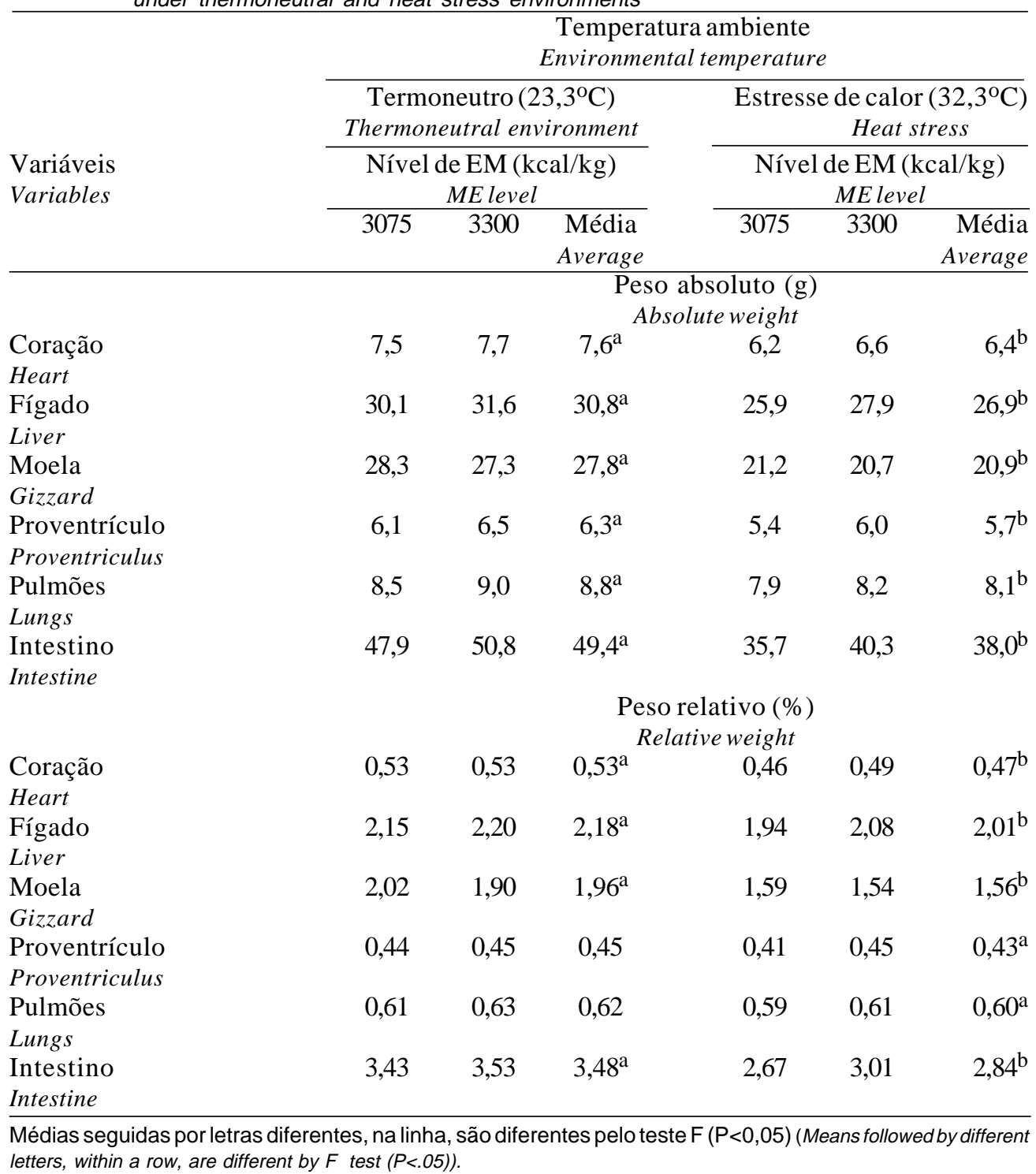

mantidos em ambiente termoneutro e estresse de calor, são mostrados na Tabela 4.

Constatou-se que as aves expostas à temperatura de $32^{\circ} \mathrm{C}$ tiveram menores $(\mathrm{P}<0,01)$ pesos absoluto $(-18,7 \%)$ e relativo $(-14 \%)$ das penas, em relação às mantidas em ambiente termoneutro. Resultados semelhantes foram obtidos por GERAERT et al. (1996a), que verificaram redução no empenamento de frangos de corte, quando submetidos a temperaturas elevadas. $\mathrm{O}$ menor empenamento das aves mantidas a $32^{\circ} \mathrm{C}$ possivelmente pode ser um ajuste, para facilitar a perda de calor para o meio ambiente, o que estaria de acordo com relatos de GERARERT et al. (1993), os quais afirmaram que aves reduzem a proporção de penas para melhorar as perdas de calor.

\section{Conclusões}

Independente do nível energético da ração, a alta temperatura ambiente influenciou negativamente o desempenho, o rendimento de peito e o peso dos órgãos vitais, bem como determinou aumento da deposição de gordura abdominal de frangos de corte.

\section{Referências Bibliográficas}

BAZIZ, H.A., GERAERT, P.A., GUILLAUMIN, S. 1996. Chronic heat exposure enhances fat deposition and modifies muscle and fat partition in broiler carcasses. Poult. Sci., 75:505-513.

BELAY, T., TEETER, R.G. 1993. Broiler water balance and thermobalance during thermoneutral and high ambient temperature exposure. Poult. Sci., 72:116-124. 
BELAY, T., TEETER, R.G. 1996. Effects of ambient temperature on broiler mineral balanced partitioned into urinary and fecal loss. Br. Poult. Sci., 37:423-433.

CHRISTON, R., LE DIVIDICH, J., SEVE, B., AUMAITRE, A. 1984. Effect of ambient temperature on the metabolic use of dietary energy and nitrogen in growing rat. Reprod. Nut. Develop., 24:327-341.

CURTIS, S.E. 1983. Environmental management in animal agriculture. 2.ed. Ames, Iowa: Iowa State University. 407p.

EFFECT of environmental on requirements of domestic animals. 1981.Washington, DC: National Research Council, National Academy of Sciences. 141p.

FERREL, C.L., KOONG, K.J. 1986. Influence of plane nutrition on body composition, organ size and energy utilization of sprague-dawley rats. J. Nut., 116:2525-2535.

GERAERT, P.A., GUILLAU, S., LECLERCQ, B. 1993. Are genetically lean broilers more resistant to hot climate? $\mathrm{Br}$. Poul. Sci., 34:643-653.

GERAERT, P.A., PADILHA, J.C.F., GUILLAUMIN, S. 1996a. Metabolic and endocrine changes induced by chronic heat exposure chickens: biological and endocrinological variables. Br. J. Nut., 75:205-216.

GERAERT, P.A., PADILHA, J.C.F., GUILLAUMIN, S. 1996 b. Metabolic and endocrine changes induced by chronic heat exposure chickens: growth performance, body composition and energy retention. Br. J. Nut., 75:195-204.

GOMES, P.C., ALBINO, L.F.T., SILVA, M.A. 1996. Criação de frangos de corte. Informe técnico. Viçosa, MG. Ano 17-no-78.18p.

HABEEB, A.A.M., MARAI, F.M., KAMAL, T.H. 1992. Heat stress. In: PHILIPS, C., PIGGINS, D. (Eds.) Farm animals and the environment. Wallingford: C.A.B. International. 430p.

KOONG, L.J. NIENABER, J.A., MERSMANN, H.J. 1983. Effects of plane of nutrition on organ size and fasting heat production in genetically obese and lean pigs. J. Nut., 113:1626-1631.

MACARI, M. 1996. Água na avicultura industrial. Jaboticabal: FUNEP. $128 \mathrm{p}$.

MAY, D.J., LOTT, B.D. 1992. Feed and water consumption patterns of broilers at high environmental temperatures. Poult. Sci., 71:331-336.
OLE MIARON, O.J., CHRISTOPHERSON, R.J. 1992. Effect of prolonged thermal exposure on heat production, reticulas motily, rumen-fluid and particulate passage-rate condtants, and apparent digestibility in steers. Can. J. Anim. Sci., 72:809-819.

OLIVEIRA, R.F.M., DONZELE, J.L., FREITAS, R.T.F. et al 1997. Efeito da temperatura sobre o desempenho e sobre os parâmetros fisiológicos e hormonal de leitões consumindo dietas com diferentes níveis de energia digestível. $R$. Soc. Bras. Zootec, 26:1173-1182.

RINALDO, D., LE DIVIDICH, J. 1991. Influence de la température ambiante sur les performances de croissance du porc. Prod. Anim., 4:57-65.

ROSTAGNO, H.S., BARBARINO JR., P., BARBOSA, W.A. Exigências nutricionais das aves determinadas no Brasil. In: SIMPÓSIO INTERNACIONAL SOBRE EXIGÊNCIAS NUTRICIONAIS DE AVES E SUÍNOS, Viçosa, MG, 1996. Anais... UFV:DZO, 1996. p.361-388.

SILVA, D.J. 1990. Análise de alimentos: métodos químicos e biológicos. Viçosa, MG:UFV. 166p.

SMITH, M.O. 1993. Parts yeld of broilers reared under cycling high temperatures. Poult. Sci., 72:1146-1150.

YUNIANTO, V., HAYASHI, K., KANEDA, S. et al. 1997. Effect of environmental temperature on muscle protein turnover and heat production in tube-fed broiler chicken. Brit. J. Nut., 77:897-909.

UNIVERSIDADE FEDERAL DE VIÇOSA. 1982. Manual de utilização do programa SAEG (Sistema para Análises Estatísticas e Genéticas). Viçosa: UFV. 59p.

ZANUSSO, J.T. Níveis de energia metabolizável para frangos de corte de 1 a 21 dias de idade mantidos em ambiente de conforto térmico. Viçosa, MG: UFV, 1998. 64p. Dissertação (Mestrado em Zootecnia) - Universidade Federal de Viçosa, 1998.

Recebido em: 28/01/99

Aceito em: 02/09/99 